\title{
WHAT TO MAKE OF THIS FLESH:
}

\author{
Gabrielle Leung \\ Ateneo de Manila University \\ gabrielle.leung@obf.ateneo.edu
}

\begin{abstract}
About the Author
Gabrielle "Bee" Leung is a senior at Ateneo de Manila University. She is majoring in Physics and minoring in Creative Writing. She was a fellow for nonfiction in the 22nd Ateneo Heights Writers Workshop. Her work can be found in previous issues of Heights and Plural: Prose Journal. She is the current editor-in-chief of Heights Ateneo.
\end{abstract}


You are fourteen years old the first time you see a man's penis. The jeepney jolts back to life; you glance to see if the rhythmic jerking motion of his hand has caught anyone else's attention. It hasn't. The road is winding. You plant your feet firmly on the metal floor to stop yourself from sliding about in your bright yellow school uniform. The man is looking straight at you, and all you can think is this is not happening. You want to close your eyes. You want to get off the jeep. You want to call your mother. Do not call attention to yourself. This is not happening. He is smiling, now, he knows he has your attention; you are transfixed, frozen, losing your balance as the jeepney picks up another passenger. You almost fall straight into his lap but you catch yourself on the metal railing. The cold stings your wrist. Throbbing. Fix your gaze at a point outside the window-there is a street sign. Try to read the name of this place so you can at least tell this story better one day. Sound the words out in your mind over and over again, until they stop being words, only letters, sounds. The sound of slick flesh, heavy breathing, the release. It seems no one else can hear it. Do not make eye contact. The next day, as you are putting on your shoes, you realize you forget the name of the street and now the moment is spinning out of control and it looms ungraspable in your memory, so you tell no one about this. 
As a young girl, you are obsessed with Greek mythology and stories of being woman enough to make men tremble. Medusa turned them into stone, Circe turned them into pigs--trembling or not, what matters is how intoxicating a smile could become. You practice yours first turned away from the mirror, imagine this is how a spell is cast. The moment you glimpse yourself, you are struck with the image of your body turned to stone, the hairs at the back of your head still sticking out, the buckteeth, the much-longed-for curve of a hip. They say Helen of Troy launched a thousand ships with only the smile on her face, perhaps the slope of her ankle. You can only dream of becoming so dangerous. At nine years old, you cannot wait to break your first heart; you imagine it, rehearsing the smile that comes after. This is what a powerful woman looks like: desired. You keep secret that you've figured it out, so no one can make anything of it. Already you learn that such aspirations only make you a target. When you return to read the Iliad in your senior year, you marvel at all the destruction, ichor spilling onto battlefield and the yards of black cloth. The funeral pyres, only. And for what? Helen smiles. The world is struck silent. 
You have only had one stalker in your life: a girl who calls you Delilah and cuts all her hair off. She stands outside your window screaming apologies. You close your windows and hope your parents think it is just another neighborhood drunk. When you tell her you do not want to date her, she walks in front of a car. Everyone tells you this is not your fault, not to visit her in the hospital, that would only make things worse, don't encourage it, be kind. You are always trying to be kind. You are trying not to think about this, remind yourself she is doing well now--you have checked. You don't like to talk about it. Other girls have had it worse. When the subject comes up, you count yourself lucky this has only ever happened to you once; none of the others come even close. Only the one who carves your name into his wrist. Only the one who never calls you sober. Only the one who sneaks into your house when you are not at home and leaves flowers on your bedside table. This is normal; you remind yourself not to play the victim, you are beloved. 
One year, you go to summer camp north of the Arctic and return strewn with friendship bracelets and other girls' $t$ shirts, their names scrawled in black letters touching the nape of your neck where no one else can see. Over the kitchen counter, you decide how to recount the story to your mother. You have been learning how to withhold. You tell your mother how the sun never sets there, how they taped garbage bags over the windows to create darkness. You choose not to tell her about the sliver of light along the edge, how it was brighter at midnight than at dinnertime. It is time for dinner now and here, the sun is already setting. She says you have gotten too tan, reprimands you for not using enough sunblock. The skin on your thighs is a shade whiter than your arms, which emphasizes the newly sprouting hair, ugly and dark black. In the shower room at camp, one of the girls offers to lend you her razor when she sees you watching her curiously. You are ashamed to say you do not know how to use the pink glinting thing, so you tell her instead that your mother doesn't shave her legs because it's another unfair standard for women, and a waste of time too. You do not tell your mother you said this, or how after that, the girl looked at you in perplexity as though you were promising you could make the days start turning again. She says she does it because the metal kissing her skin makes her feel in control. And then she picks up her shaving cream and steps into the blossoming mist. The sun blocks out the aurora borealis, so you never saw the green lights dancing in the sky. You could have sworn you caught a glimpse once, looking out at the bright evening sun from a little bathroom window. It was only a flicker. Tell your mother that, instead. 
A professor tells you he must send you out of the classroom when you take off your jacket to reveal a sleeveless dress. It is sweltering, but you put it back on and grit your teeth so as to not be a disruption. Your male blockmates look at you as though encouraging you to make a scene. You pick up a pen and start taking down notes again. You are pressing down on the paper hard enough to tear. Breathe. A woman you admire once told you to pick your battles, to know when you can win them and to recognize when an outburst would only be futile. You do not want them to talk about you as that girl (you know they already do), and you are more than a little guilty at thinking yourself oppressed--shut up, this is just the deal. This is why when the boy you call your friend keeps darting his eyes down to your chest, you say nothing, but pull your shirt up a little higher. You allow his eyes to linger, because you can't be certain you are not just imagining things. This is why when another friend spreads rumors about how you led him on, you accept the birthday present he gives you with a smile, but you start avoiding him in the halls. This is why when the man in the truck yells Happy Valentines' Day and tells you how exactly the two of you could be celebrating, you only walk a little faster and pretend you didn't hear anything. You are afraid you are now a part of the problem--your silence will be read as acceptance --you only want to make something beautiful out of all this. 
The first time a boy kisses you, you are on the beach under stars. The campfire stopped burning hours ago, but you can still see its embers. There is too much tequila, so he tells you to take another shot. You are dizzy, so you lay down on the sand to look at the sky--you can see all the stars here, and it is colder than you thought. All of a sudden, he is on top of you and you freeze up. You do not want him and the smoke clinging to his skin, but you enjoy being wanted, so you pause to consider your options. Before you can say stop, he takes your pause as invitation. You do not try to change things anymore. You rehearse how the story goes before you claim it later as your own: the warmth of another body and his wandering saltwater-stained hands; this is what you have always wanted; this is what you had been planning all along. This is happening to your body, now. It doesn't feel good, exactly, but it feels like something. You want to say this is not a violation. He is a good person. You never told him no. You can lie there while it happens. The truth is, there is a part of you that enjoys this. The next morning, you step out of the tent you find yourself in and sit on the shoreline, watch the sky turn pink and the sand disappear into the sea. 
You watch as the American man on television talks about grabbing women by the pussy. You are dumbstruck when someone says he is going to be president. There is a song about blurred lines that is always playing on taxicab radios. The men want to watch the senator's alleged sex tape at her hearing. They call her a disgusting pig. People are concerned about the Stanford rapist's future. He could have been an Olympian. Baby it's cold outside--what's in this drink? Be quiet. They sit at a bench and yell numbers to rate women passing by. A man shoots six people because no one wants to fuck him. The college boys tell a girl to spread her legs wider. The boy on that show everyone watches tells his sister how beautiful she was on the night of her rape. A host berates a woman for wearing shorts and her attackers' drunkenness. She should have known better, he says. The President kisses a supporter on the mouth, asks her to sit on his lap. He says he was ogling his second-in-command's knees because her skirt was too short. You know what that gaze must feel like. 
One of your girl friends calls you a prude because you won't ask the man sitting in the corner out. She says it's because you are too much trapped by the patriarchy to even try, or else because you just don't have the balls to put yourself on the line. You want to say you have never had any balls at all, and besides, it isn't that, you are only tired. Instead, you tell her that you only like people who like you first, and you can all laugh about this, as much an admission of guilt as it is an attempt at liberation, all the edge in her voice erased itself; you can tell her another story now. All of you know what it feels like to want, to be wanted--how there is power in both, but certainly more in one of them. You're sick of thinking about power so much, you just want to think about this song on the radio, how it makes you want to stand up and dance. The girls are talking about what they would do if they ever needed an abortion, who they would call first, where they would go. You are debating the necessity of telling the father of the unborn, and you collectively decide it would be all right not to. Not that he doesn't have a right to know. It's just simpler that way, withholding. Now someone is talking about her boyfriend, and how much they fuck, and it's the feminist thing to do!, and someone says the man in the corner has been staring at you, and you roll your eyes, and she sighs, and you are tired of being thought of as so angry, and you say you're going to the washroom. It's grimy and smells like a dead animal, but you take the time to reapply your lipstick. Blot your lips. There's a number scrawled on the stall door. It says to call if you want to have a good time. 
He takes your photograph and you think you have managed to remain serene this time, but he shakes his head, you have frozen up again, your elbows locked awkwardly to your body. It's all right. The boy is smiling, he says the pictures are better when you don't know they're being taken. You are frustrated but take his word for it. You've never seen yourself unmediated--only in mirrors or photographs, only an arm or the lock of hair that keeps flying into your face, only through the eyes of boys like this one when they tell you how much they want you. You worry your anxiety makes you shallow; you'd like to say you want not to look in a mirror again, but if you're being honest, you'd miss it. One day, he asks to take your photograph, but you never make it beyond your closet. You're lying in a pile of clothes on the floor, nothing is right. What you mean to say is there are parts of you that want to remain unseen. A photograph means being captured in another's gaze and you would like to remain fully your own in this moment, where you teach each other what it means to inhabit your wanting: you are better at reading maps and he can speak to strangers. When you get to the ocean, you find a condom floating in the waters, so you walk along the beach counting bright blue jellyfish washed ashore. Later, in an empty bathroom stall, you trace your fingers down the small of his back and smile at the shiver. Your second favorite photo from that day is of your shadows almost intertwined. Your favorite is of the sky. 
The month before you leave for college, you watched a thousand women teach you about your own face and how to wield it. A friend teaches you the proper way to apply concealer, how to pick out the undertones and what pigments could disguise. Peach to hide dark circles, but never on acne marks, it would only draw further attention. Neither of you are certain what yellow is for, but you take photographs of yourselves until you forget--your camera is a pale pink and now you can imagine yourself as an object of desire. This involves staring at your face until you know all its angles. You have never quite mastered smiling, so instead you allow your mouth to hang open, but only a little. You hope no one will notice the discoloration of your teeth or the thinness of your lips. The photos come out overexposed, but when you look at them long enough, you start to imagine yourself beautiful; you are still trying. You ask your mother for a curling iron for Christmas to tame hair that never lies flat, practice until you no longer burn skin, or at least until you tolerate the heat. You learn words for all the things that ever upset you about your own face, which means you can control them. One of your eyes is a monolid and the other isn't-you have always cursed this asymmetry-but if you only practice the swoop of black eyeliner enough, you can disguise this, too. When you sit in front of the mirror, turn your face to catch the light, ignore the sparseness of your brows, the hairs sprouting where they are unwanted, there will be time for this later. Draw the line on above your eyes, imperceptibly shaking. Wipe the ink off. Repeat until your hands are stained black and your eyes tear up and you can imagine the aurora borealis to life again, an ocean refusing the shoreline, your skin smooth as it has ever been. This is how you begin to desire yourself: your eyes rubbed red and raw, but there is a cooling cream for that. The pot is clear glass, stark white inside. Let it sink in, gentle. 